\title{
Die Geister, die ich rief
}

\section{Matthias Scholer}

Online-Redaktor

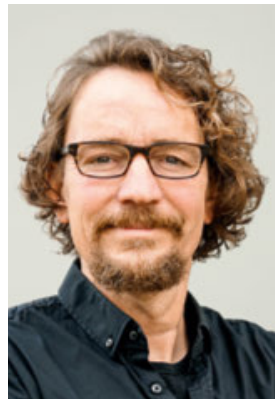

mscholer[at]emh.ch
Die Ausgabe Nr. 3 der SÄZ in diesem Jahr spiegelt das Spannungsumfeld, in dem wir uns geschäftlich und privat befinden, exemplarisch wieder. Auf der ersten Umschlagseite wirbt ein Labor für dessen neue App, dank der man sich die neusten Laborresultate seiner Patienten direkt aufs Smartphone senden lassen kann. Einige Seiten später findet sich ein Bericht über die Trendtage Gesundheit 2017, bei der die neue Strategie «eHealth» Schweiz im Mittelpunkt steht. Im Rahmen dieser Tagung wurden Themen wie die Einführung und Verbreitung des Elektronischen Patientendossiers, Mobile Health und eHealth Literacy behandelt und der regulatorische Handlungsbedarf in diesen Bereichen erörtert. Abgerundet wurde diese SÄZ-Ausgabe dann durch einen Beitrag von Jean Martin unter der Rubrik «Zu guter Letzt». Mein Redaktionskollege schildert dort trefflich, wie unsere Sinne immer mehr an Bedeutung verlieren, da wir unsere Umwelt immer weniger auf direktem Weg, sondern immer mehr über technische Hilfsmittel begreifen.

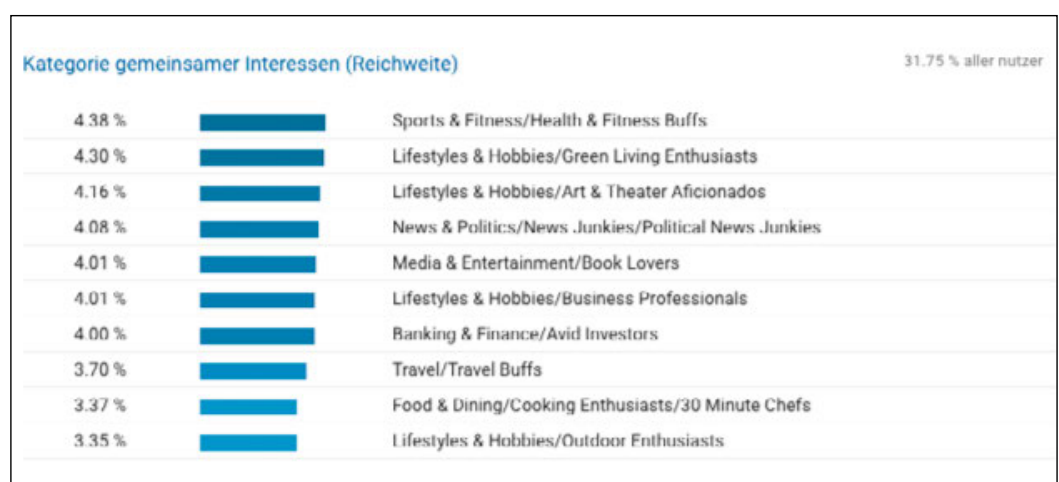

Abbildung 1: Die Interessen unserer Online-LeserInnen.

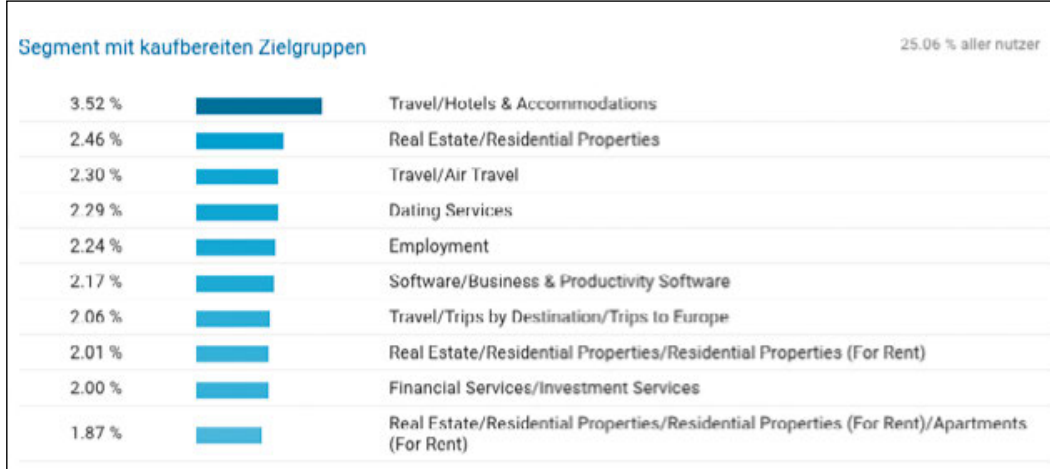

Und während wir also unsere (Um-)Welt mittels Smartphone, Tablet oder Laptop zu begreifen versuchen, hinterlassen wir Spuren. Spuren, die zwar grösstenteils automatisch anonymisiert werden, aber trotzdem noch für viele interessant sind. Zum Beispiel für mich in meiner Funktion als Onlineredaktor bei der SÄZ. Für uns vom Schweizerischen Ärzteverlag EMH ist es unabdingbar, zu analysieren, wer von wo wann und mit was auf unsere Zeitschriften im Netz zugreift schliesslich beobachten wir in den letzten Jahren auch bei der SÄZ einen kontinuierlichen Trend weg vom Print hin zum Onlinelesen. Ich habe Ihnen in meinem Beitrag "Ein Blick hinter die Kulissen" bereits einige Analysedaten bezüglich des Leseverhaltens und der Demografie unserer Online-Leserschaft vorgestellt [1] Diese Daten werden uns als Betreiber und Inhaber einer Webseite von Google kostenlos zur Verfügung gestellt. Die meisten der Datenkategorien sind unspektakulär wie beispielsweise die Klickrate, die Verweildauer oder die Geschlechtsverteilung der User. Gewisse Daten stimmen mich jedoch eher nachdenklich. So kategorisiert mir Google ungefragt die User nach Interessen (siehe Abb.1) oder in welchen Bereichen Sie, liebe Online Leserinnen und Leser, im Netz einkaufen (siehe Abb. 2). Das ganze natürlich mit dem Ziel, Digital Marketers einen Mehrwert zu bieten

Natürlich überlege auch ich mir in diesen Momenten, ob ich künftig nicht wieder barzahlend in Geschäften einkaufen sollte. Doch dieser innere Aufstand macht immer relativ rasch einer Bequemlichkeit Platz, zu der die Kreditkarte, Online-Einkäufe und die Zeitungslektüre im Netz gehören. Wohlwissend, dass wir die Digitalisierung weder aufhalten noch bremsen können. Ich befürchte sogar, wir werden sie kaum kanalisieren können. Getreu nach dem Motto: Alles was machbar ist, wird gemacht. Auch wenn gilt: Nicht alles, was machbar ist, ist richtig.

\section{Bildnachweis}

Screenshots $\odot$ Google Analytics

\section{Referenzen}

1 Scholer M. Ein Blick hinter die Kulissen. Schweiz Ärztezeitung. 2017;98(25):840 